\title{
PROGRESS, MOBILITY AND URBAN REGENERATION IN A TRADITIONAL NEIGHBOURHOOD: EL ENCINO, MEXICO
}

\author{
ALEJANDRO ACOSTA COLLAZO \\ Habitat Design Department, Autonomous University of Aguascalientes, Mexico
}

\begin{abstract}
During the second half of the 20th century, the cities in Latin America began to grow rapidly, and the historic built environment has changed since then. Some of them preserved historic architecture, some others changed dramatically, and a few combined historic buildings with factories and the dynamics of new ways of mobility. This is the case of the neighbourhood: El Encino in Aguascalientes, Mexico. The factory: JM Romo was established in 1957 in El Encino. It pursued welfare and prosperity in the neighbourhood, helping with economics sustainability, such as a theme park development, building an indoor basketball court and schools for its workers. Somehow a social sustainability was achieved, but there was a loss of the historic buildings that were bought by the factory -and then they were torn down, and trucks changed the mobility on the narrow streets of the historic neighbourhood. So now the urban image of El Encino is a combination of the factory facades, parking lots and historic buildings. To find out about the social benefits to the factory workers and the opinion of the inhabitants of the neighbourhood two different surveys were conducted. Some of the results showed that the factory has pursued facilities for their workers, but not for the whole neighbourhood. Also, some residents built a garage in their houses because of the increasing traffic. Fortunately, the city planning has considered in the last years restoring the facades of the main houses, also changing the pavement, and building a new museum. Besides, the Guadalupe Posada Museum preserves the famous printings of this Mexican designer. It is through the analysis of the factory impacts (social and mobility), the developing of the neighbours to improve their own resilience and the late urban planning that the site can be preserved as part of a sustainable city.
\end{abstract}

Keywords: urban image, cultural heritage site, mobility, city planning, sustainable city.

\section{INTRODUCTION}

A sustainable city should consider the preservation of its cultural heritage sites. The main objective in this paper is to evaluate the social and mobility impacts of the JM Romo factory in El Encino neighbourhood. Also, to study the way the inhabitants of this neighbourhood improve their own resilience. The examination of the recent urban preservation in the site is convenient to understand the divergence between progress and historic preservation.

Since the JM Romo factory was established in the year of 1957 in the neighbourhood: El Encino in Aguascalientes City, a steady expansion of the factory started to disrupt the original historical urban core. The owners of the factory bought many of the private properties, no matter their historic values. The lack of a regulatory agency made the acquisitions of lands and old buildings easier. It is worth to mention that the delegation of the National Institute of Anthropology and History (INAH) didn't establish their agency until 1989. Nowadays, houses and factory - one next to each other - share the old neighbourhood. Also, there is a reduction of urban basic services. In contrast with the urban alterations, the factory began designing and creating services to its workers, for example: an amusement park, apartment buildings, schools and spaces for sport activities, among others. In fact, the company used some of the properties acquired to build warehouses, parking lots, and truck parking spaces. The industrial expansion faced an opposition from the neighbourhood that refused to sell all their houses next to El Encino church, because people identified themselves with the 
traditions and symbolisms expressed on the old neighbourhood and the emblematic garden. The old and new building contrast gave place to a sui generis urban landscape, including some objects in the amusement park -with imaginary connotations of distant cultures, like African masks, American old west towns, medieval castles, etc., in total difference to the original architecture of the neighbourhood. The monumental factory and its mobility resulted in diverse contents - in aesthetics terms. A survey was applied to identify the impact of the industrial mobility, and another survey was applied to identify the social benefits in the neighbourhood. The research concluded in two different aspects: Social benefits and mobility, including social resistance - which stopped the advance of the building chaos in the neighbourhood. Therefore, the changing urban landscape became recognizable through the study of urban history. In recent times, the government tried to preserve the remains of the convent of the temple - that became the Guadalupe Posada Museum, including a new contemporary façade. Also, the government remodelled sidewalks, streets and some buildings. The valuable architecture of the Neighbourhood: El Encino can be identified thanks to the analysis of social aspects but including elements of the historic urban landscape.

\section{METHODOLOGY}

I started this research determining the social benefits of the JM Romo factory to its employees, and exploring the impact of the factory mobility to El Encino neighbourhood. It was convenient to design two surveys for this paper: one about mobility and another one about the social benefits. With the purpose to design the surveys of the first case (mobility) the following objectives were established to: 1 . Identify the daily mobility mode of the respondent, 2. Inquire about the effects caused by vehicles of the factory in neighbouring streets, 3. Identify if the vehicles of the factory use the neighbourhood streets to park, 4. Determine if mobility of the factory causes house alterations, 5. Identify possible environmental problems caused by the mobility activities of the factory, 6 . Inquire about the impact the activities of the factory have on the urban mobility (vehicular) of the area, 7. Inquire about the impact that the activities of the factory have on the urban mobility (pedestrians) of the area, 8. Inquire into the perception of safety/insecurity associated with the daily mobility of the inhabitants of the area, 9. Inquire into the degree of recognition of the inhabitants related to the characteristics of the urban space in the neighbourhood (streets). This is linked with: assess of pertinence of the location of the factory, 10. Inquire about the correlation between vehicle activities of the factory and the perception of insecurity related to the mobility of the inhabitants of the area, 11. Recognize the opinion of the inhabitants of the neighbourhood about the mobility alternatives in the area, 12. Inquire into some difficulties of mobility of the inhabitants of the neighbourhood related to the activities of the factory, 13. Inquire about the degree of recognition of the inhabitants related to alternative and sustainable ways of urban mobility, 14. Inquire about the degree of recognition of the inhabitants related to the efficient/inefficient infrastructure oriented to the use of sustainable means of mobility in the neighbourhood, 15. Inquire about the degree of social recognition of the inhabitants of the neighbourhood towards the factory, 16. Identify the urban transformations in the neighbourhood as a result of the arrival of the factory, 17. Inquire if the inhabitants of the neighbourhood take advantage of the theme park owned by the factory, 18. Identify the urban transformations in the neighbourhood as a result of the factory facilities and mobility.

In the survey of social benefits, the following objectives were established to: 1. Identify if the respondent is an employee of the factory or a retired worker, 2. Inquire about the social recognition of the factory, regarding the provision of health facilities, housing, education, etc. 3. Record if the factory has facilitated housing loans for its employees. 4. Identify if the 
factory offers social insurance and benefits to its employees, 5. Inquire into the employees' perceptions about the attention of the factory to their needs, 6 . Determine if the factory promotes improvement of training programs for the employees, 7. Inquire if the factory provides proper working tools and support to the employees, 8 . Identify whether there is an incentive model in the factory, or any scheme of job growth that would allow employees to move up to better job levels, 9. Inquire if the factory provides basic education for its employees' wives and children, 10. Inquire about the employer-employees relations and identify the mechanisms of conflict resolutions in the absence of a union, 11. Identify the infrastructure of the factory built for basic social benefits, 12. Recognize the infrastructure of the factory related to basic social benefits, 13. Determine if the factory allow employees and their families access to leisure areas, 14. Inquire if the factory encourages the practice of sports among its workers and families, 15 . Identify if the factory provides additional benefits to the employees. Also, identify at what level of scale this kind of benefits are provided, 16. Recall if the factory provides additional benefits to the employees. Also identify at what level of scale this kind of benefits are provided, 17. Inquire into the employee's perception about attention and commitment the factory shows around their needs and those of their families.

The methodology used to resolve the scientific problem could be situated in qualitative research. Linda Groat and David Wang say that qualitative research deals in the interpretation of contemporary situations. It places particular emphasis upon the role of the researcher as a vital part of the research outcome [1]. The surveys were used to articulate the points of view of society with the research arguments and to analyze the results, according to urban preservation theories and history in the cultural heritage site.

\section{THE SURVEYS ON MOBILITY AND SOCIAL BENEFITS}

The questions asked on the mobility survey were: 1 . What is your favourite mode of transportation? Select: Car or motorcycle or bicycle or public transport, other. 2. Do the vehicles of the J.M. Romo factory have a parking lot? 3. Do the factory vehicles park on the streets of the neighbourhood? 4. Did you have to build a garage due to the amount of vehicles parked on the street? 5. Have you ever been disturbed by the noise made by the factory vehicles? 6. Do you think the factory increase traffic in the neighbourhood? 7. Do you think the vehicles of the factory are a risk to pedestrians? 8. Do you feel safe walking on the streets close to the factory? 9. Do you consider the streets in the neighbourhood are suitable for the transportation of goods of the factory? 10. Do you consider that factory vehicles increase the risk of accidents? 11. Do you consider public transport is good enough around the factory? 12. Have you had any difficulty moving from one street to another due to the cargo vehicles of the factory? 13. Do you think bicycles or other modes of nonpolluting transportation are a good option to move around the neighbourhood? 14. Do you think the streets in the neighbourhood are well designed for cycling? 15. Do you think the factory is valuable to the neighbourhood? Why? 16. Has the factory grown in recent years occupying more blocks in the neighbourhood? 17. Can you (and your family) enter with no restriction to the theme park development? 18. At some point the factory has shown interest in acquiring your property?

The questions asked about social benefits were: 1 . Are you an employee of the J.M. Romo factory? 2. Do you consider the factory has taken actions to benefit the neighbourhood? 3 . Has the factory supported you to purchase a house? 4. Do you have employment benefits according to labour laws and regulations? 5. Do you consider the factory is concerned about your physical, mental and economic well-being? 6. Does the factory often teach you the skills for the job? 7. Has the factory ever provided you proper equipment and tools needed to carry out the work? 8. Does the factory encourage you to improve your job through bonuses or 
awards? 9. Has the factory provided education support for your wife and children? 10. Do you think the factory solve in a good manner the employer-employees' conflicts? 11. Does the factory have dining services? 12. Does the factory have a transportation service? 13. Do they give you access to the recreation facilities in the theme park? 14. Does the factory have sports facilities for workers? 15. Does the factory provide benefits, such as food and groceries for employees, or free gasoline vouchers? 16. Does the factory provide you additional benefits such as life insurance or accident insurance? 17. Do you think the factory enhance your life quality?

\section{RESULTS AND DISCUSSION}

Based upon the results of the two surveys I identified that the results were opposite. This means that most of the people inquired about mobility accepted they were uncomfortable with the location of the factory inside the historic neighbourhood. But the survey about the social benefits of the factory to the workers demonstrated a general acceptance of the factory in the neighbourhood. The groups of ages of inquired people are shown in Fig. 1.

Young people (between 20 and 29) were more willing to answer the questions of the survey. Also retired people attended properly the inquirers. In order to examine the nature of the mobility problem inside the neighbourhood: El Encino, it became convenient for the research to know if the factory workers preferred to park on the streets or in the factory parking lot. $46 \%$ of the inquired people (Fig. 2) mentioned the workers preferred to park on the streets, causing a problem of street parking in the neighbourhood. This situation motivated some of the inhabitants to build a garage, altering their houses and their facades. As a result, the image of the cultural heritage site changed too. Furthermore, excessive use of cars in residential areas produces air pollution and modifies the inherent features of residential landscapes, especially in quarters without green areas.

In general, the results of the mobility survey showed the expansion of the factory that modified the urban landscape and the way people lived in the neighbourhood (Fig. 3). But also, it shows the factory decided to stop buying houses around to tear them down.

Examining the results of the mobility survey somehow it can be inferred the people who live around the factory are uncomfortable with it. During the second half of the $20^{\text {th }}$ century there was a loss of the historic buildings that were bought by the factory -and then they were torn down. During this expansion of the factory the people faced the disadvantage and decided to stop selling their homes to the factory. El Encino became a resilient neighbourhood during the decade of the 1990s.

Recently the factory decided to build new facilities in Jesús María, away from the historic centre. But the factory in El Encino continues functioning regularly. So, the urban resilience in El Encino continues too. The clue to preserve the site is the inclusion of friendly urban

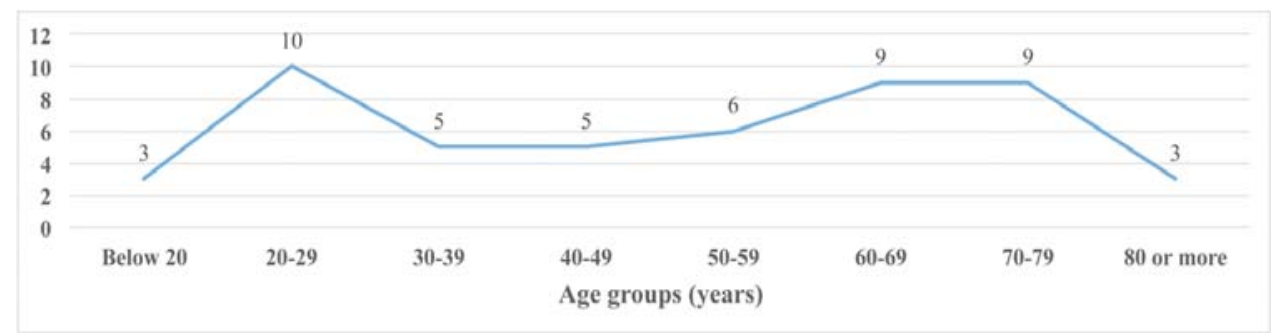

Figure 1: Mobility survey. Groups of ages of respondents. (Source: Acosta \& Esparza, 2017.) 


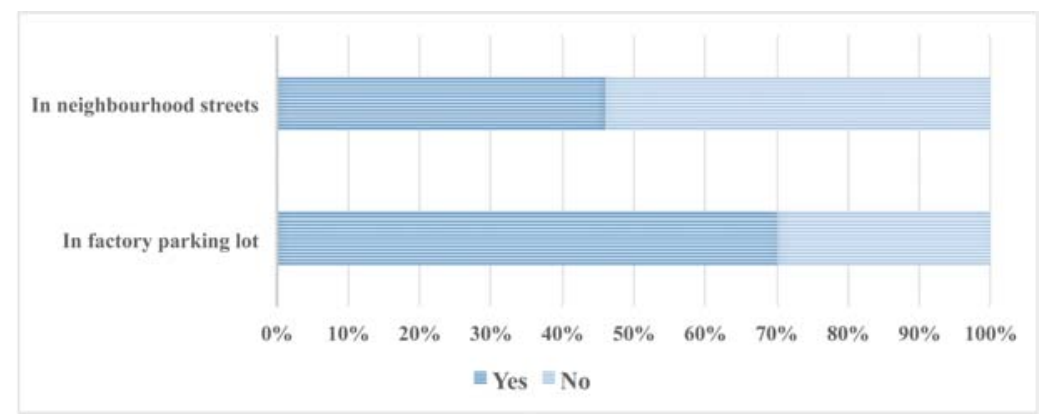

Figure 2: According to the mobility survey, $46 \%$ of the inquired people mentioned the employees of the factory parked in neighbourhood streets. Also, when people were inquired if the factory had a parking lot for employees, $70 \%$ answered affirmatively. (Source: Acosta \& Esparza, 2017.)

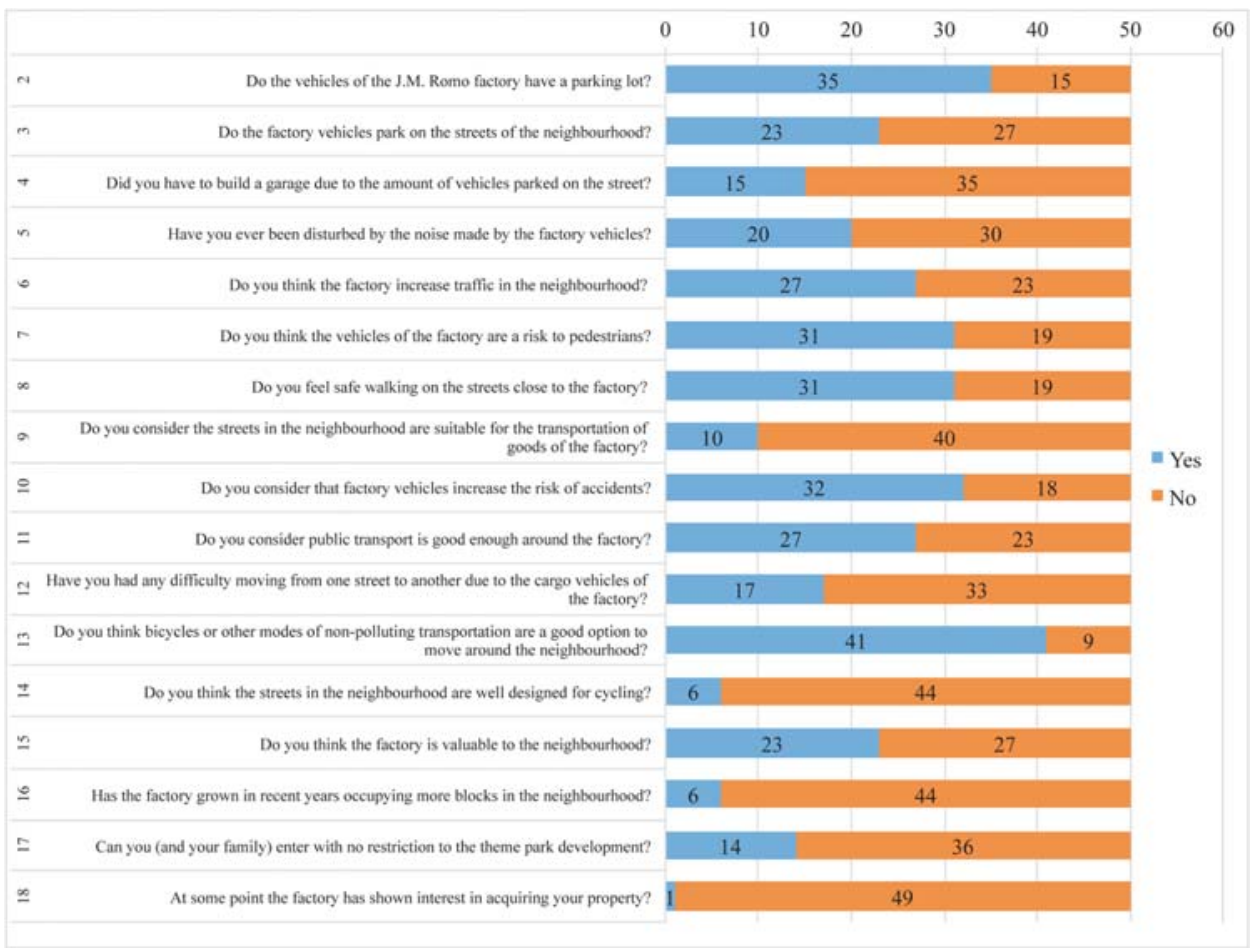

Figure 3: A global result of the mobility survey demonstrates the factory next-door neighbours are uncomfortable with the factory inside the neighbourhood. (Source: Acosta \& Rodríguez Valdez, 2017.)

renovations in the city planning, in order to make the place a quieter place to live in, decreasing the context of vulnerability. Also, the main church, the square, the museum and the historic urban landscape should keep as a magnet for tourists and a cultural core for the neighbourhood. 
The loss of historic architecture not only occurred in El Encino neighbourhood, but in the whole historic centre. Recent local researches have demonstrated the loss of historic architecture was about $79 \%$ from the original buildings the old city used to have in 1885 . Once the delegation of the National Institute of Anthropology and History (INAH) established its quarters in Aguascalientes in1989 the local regulation about tearing down historic architecture began.

The survey about social benefits was focused basically in the opinion of the factory employees. In order to relate the results with the mobility survey first of all they were inquired where they lived and the way to get to work. I found out that most of them lived in el Encino neighbourhood or in San Fernando (Fig. 4). This last place is a quarter built by the factory, specially designed for the workers.

Filtering the research results of the social benefits survey, it can be observed there are aspects in common like: proper equipment and tools, job training, bonuses or awards, support for housing, employee benefits according to labour laws and education support for wife and children (Fig. 5). The workers in general had the same opinion about the support of the company to them and to their families.

The results of the survey about social benefits of the factory to its employees showed positive opinions about the employer (see Fig. 6). Some of the older workers mentioned the first owner of the factory was almost like a mentor to them. This because he always tried to help the workers, he built a residential area for them and promoted employee benefits. The best evaluated queries were those related to recreation facilities of the factory - like the theme park, including sports facilities, specially built for the workers and their families.

The lack of development regulations during the second half of the $20^{\text {th }}$ century in the city allowed the construction of the company in the core of the traditional neighbourhood: El Encino.

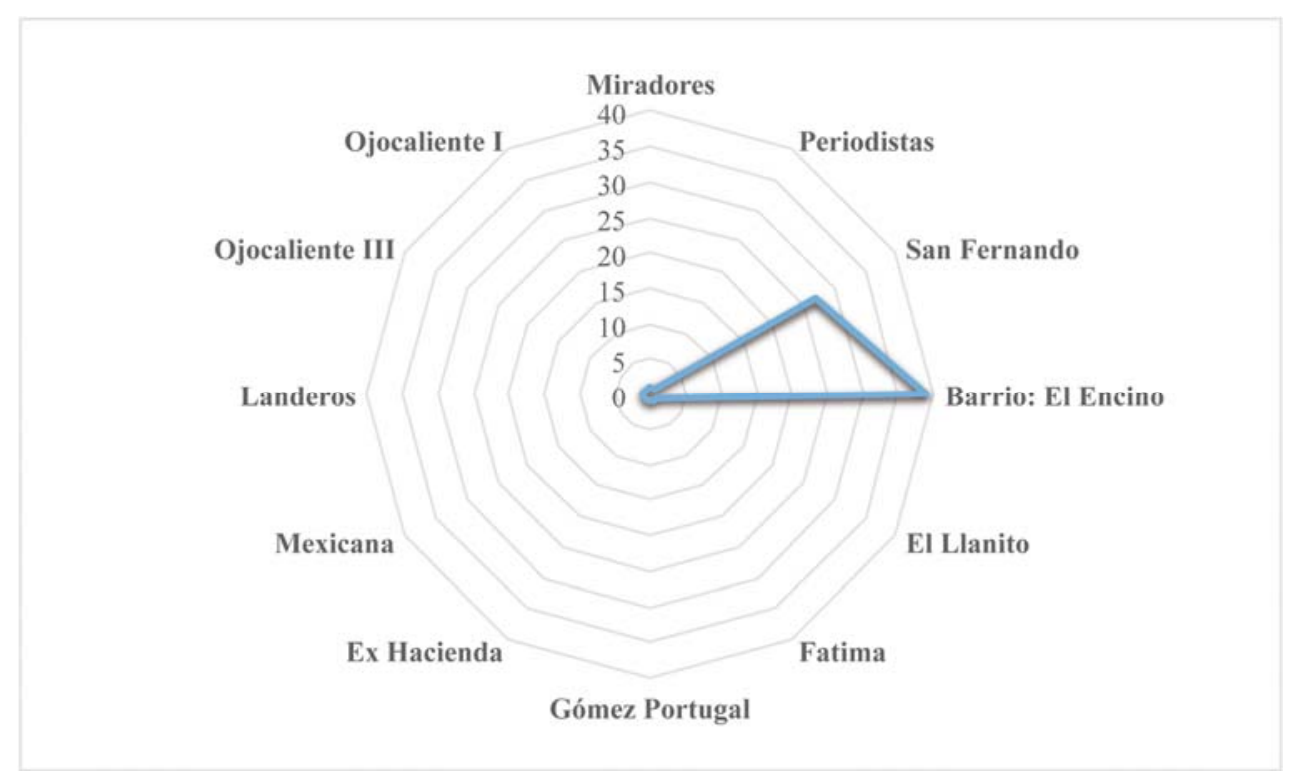

Figure 4: Most of the inquired workers in the social benefits survey lived in El Encino (39) and 37 lived in San Fernando, the residential area built by the factory for its workers. (Source: Acosta \& Esparza, 2017.) 


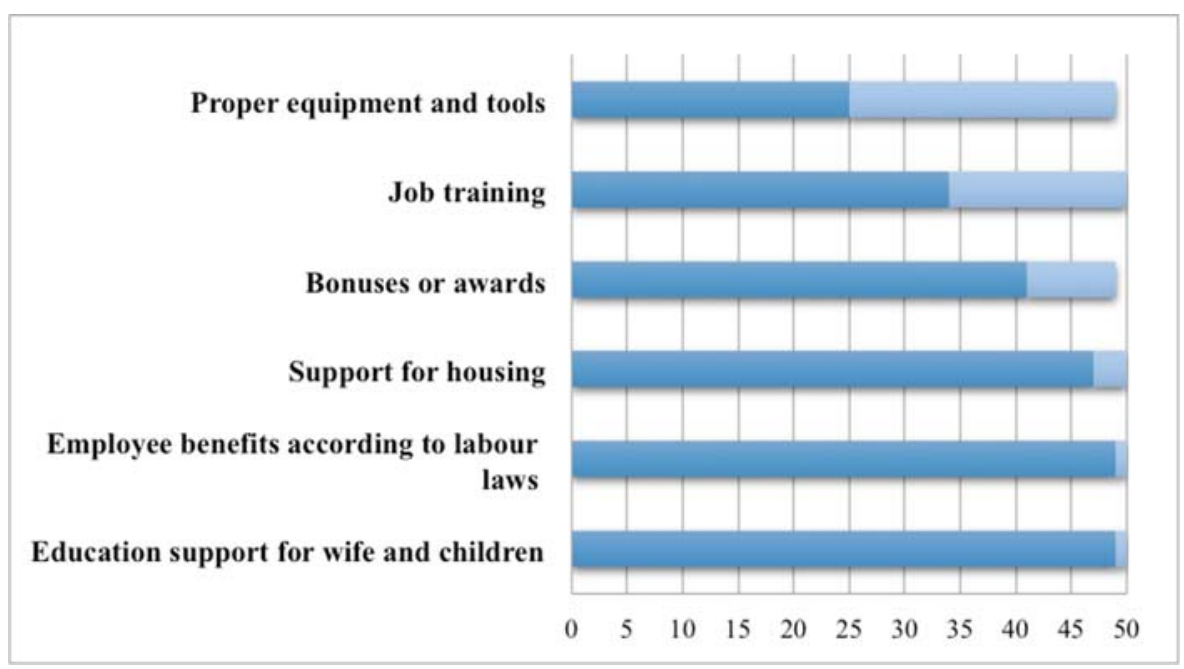

Figure 5: Employee benefits. Most of the inquired workers accepted the factory helped them with social benefits. (Source: Acosta \& Esparza, 2017.)

There have been several city government administrators who tried to improve in land use planning, but the factory never gave up on moving somewhere else (including modern industrial parks). In the pursuit of a sustainable city it is necessary to promote healthy and functional neighbourhoods. This means residential neighbourhoods with a quiet nature. Inhabitants in El Encino weren't asked their opinion about the founding of the factory in the neighbourhood. Also, the delegation of the National Institute of Anthropology and History (INAH) didn't establish its agency until 1989, so there was no regulation of the factory heights. Heavy trucks have negative impacts in the residential area, including noise, pollution and vibration of the houses. In fact, when answering the queries, a person mentioned the machines they used in the factory would vibrate his house.

The image of the neighbourhood changed dramatically with the arriving of the factory facilities and especially with the theme park. The historic buildings and the permanence of the identity juxtaposed with the imaginary African culture symbols, American old west towns, medieval castles (see Figs 7 and 8), etc. So, the second half of the $20^{\text {th }}$ century in the traditional neighbourhood was a period of change and permanence. Robert Ventury says: Las Vegas's greatest growth has been since World War II. There are noticeable changes every year: new hotels and signs as well as neon-embossed parking structures replacing on-lot parking on and behind Fremont Street. Like the agglomeration of chapels in a Roman church and the stylistic sequence of piers in a Gothic cathedral, the Golden Nugget casino has evolved over 30 years from a building with a sign on it to a totally sign-covered building [2]. So, urban architecture is always changing in not regulated sites. During the last decades, the government has been restoring a few historic buildings in the neighbourhood and included a contemporary building next to the old convent of the church and the J. Guadalupe Posada Museum (see Fig. 8). This Museum preserves Posada's famous printings. They remodelled a street around El Encino church and became fully pedestrian.

Also, they painted facades of historic houses and installed sculptures. Somehow the regeneration works have recovered the historic site and the main square became more pedestrian friendly. The community also has supported the painting restoration works inside 


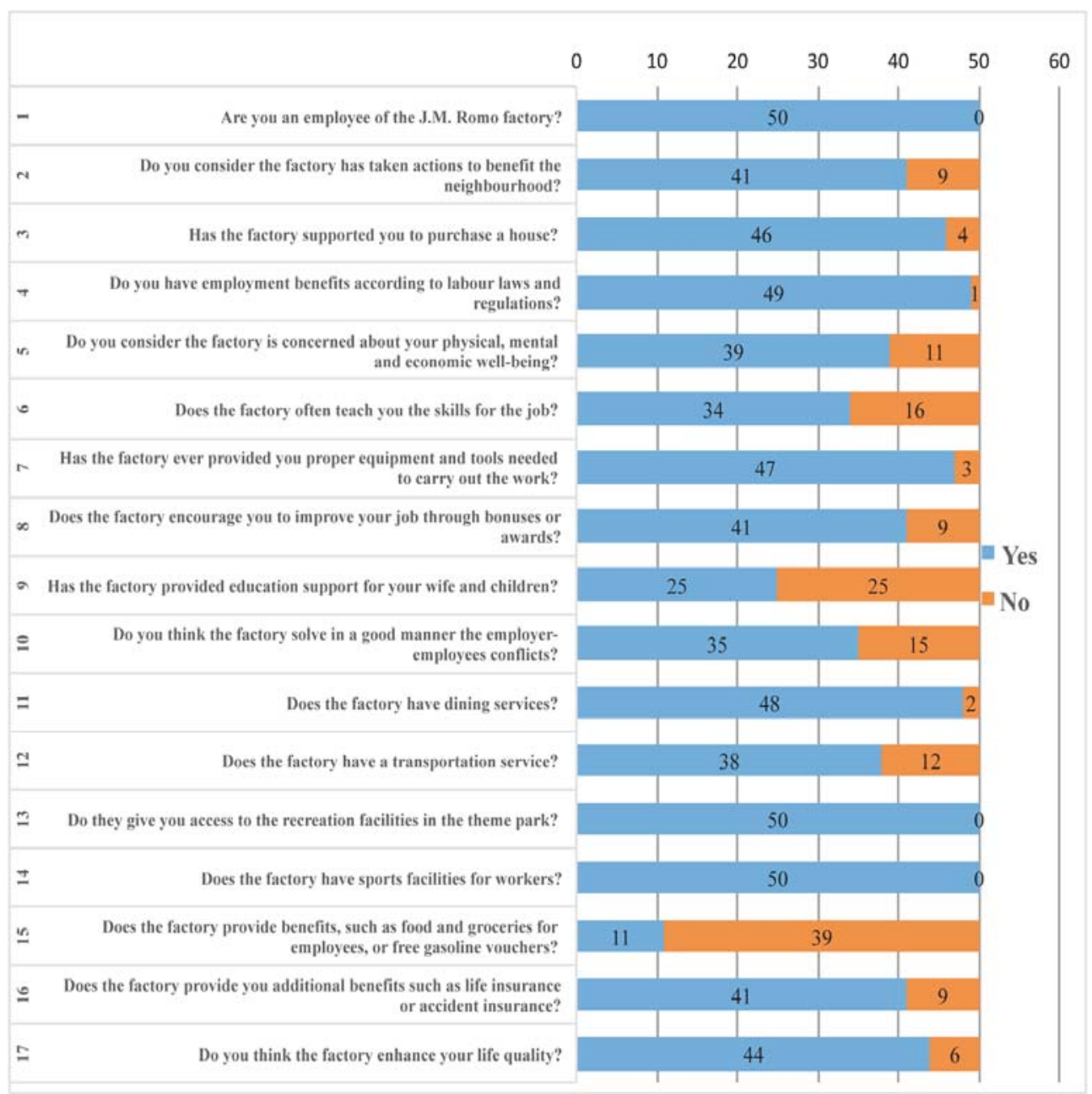

Figure 6: A global result of the social benefits survey demonstrated that employees agreed with the location of the factory in the neighbourhood. (Source: Acosta \& Rodriguez Valdez, 2017.)

El Encino church and helped enabling access steps at the entrances of the church, including ramps for people with disabilities and older people.

The narrow streets of the neighbourhood don't allow too much room for new cycling routes, so there's still a lot to do in urban preservation activities. Miguel Ruano says sustainable urban development should focus primarily on restoring degraded sites rather than urbanizing precious and increasingly scarce natural or agriculture areas. Urban planners and designers are more often than not confronted with complex existing urban conditions, frequently in a state of decay, which public and/or private bodies seek to redress. 'Urban renewal', 'redevelopment' and even the vilified 'gentrification' are some of the more frequent approaches in such cases [3]. 


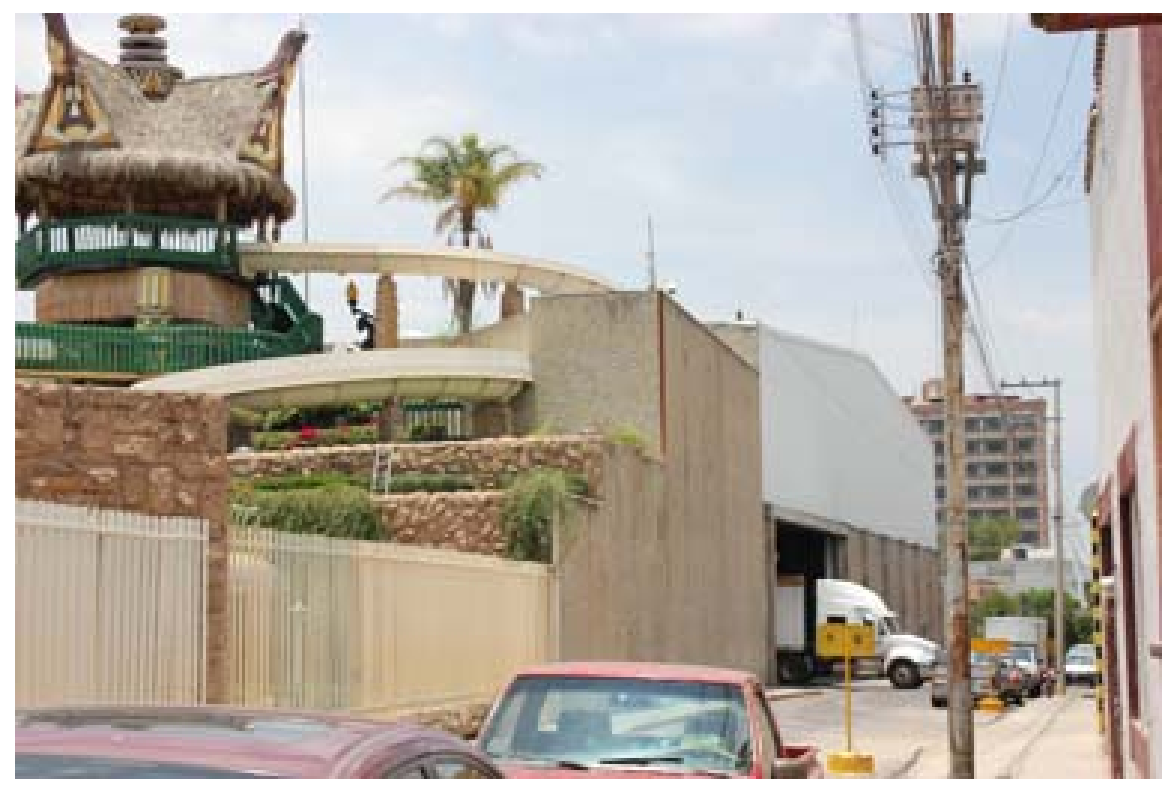

Figure 7: Incompatible land uses cause mobility problems in the traditional neighbourhood: El Encino. (Photo: Rodríguez Torres, 2017.)

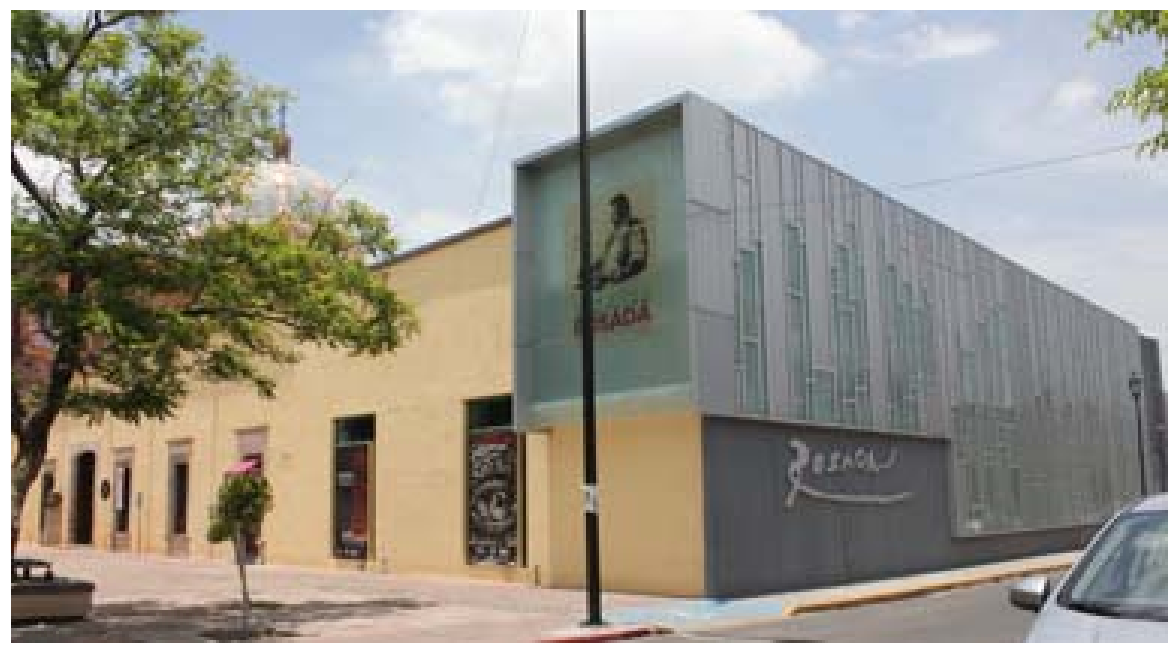

Figure 8: The new hall of the Guadalupe Posada Museum accentuated the street corner. (Photo: Rodríguez Torres, 2017.)

\section{CONCLUSIONS}

Even though the results of the social benefits survey for the company workers were positive the progress in the neighbourhood was not that evident, but in a few houses and the same factory facilities. So, the pursuit of real progress to workers is not an ideal for the company. But it's interested in helping the workers with basic needs, and in recreational opportunities. 
It surprises to know all the workers of the factory don't join a union. The causes were not identified in the surveys.

Why the neighbourhood: El Encino should be preserved? Even though the factory is in the core of this historic quarter, there are enough historic buildings to preserve. Philip Wilkinson says: Buildings from the past play a special role in the identity and pride of an area. Restore an old building, repair its broken roof or its cracked walls, or replace its peeling decoration, and you can give an immense uplift to a neighbourhood. First and fore, this uplift is psychological - people feel better about their area if the most important buildings are cared for and can be shown off to admiring visitors [4].

The problem of mobility in the neighbourhood produced by the factory requires consideration in the city planning. A hierarchy design of transit could reduce inner neighbourhood deterioration. Guy Battle and Christopher McCarthy mention: The key to a sustainable transportation system is the implementation of a transport hierarchy which gives priority to the pedestrian and public systems above the car. This does not necessarily imply positive discrimination against the private car: successful implementation of such a hierarchy can be achieved by merely creating an environment which does not cater for the car. This can be accomplished by limited parking spaces, traffic calming, cheap mass transit and by establishing a network of roads unsuitable for vehicular traffic: pedestrian, cycle based; mass transit (public); car. The hierarchy chosen will dictate which modes have 'design' priority over others [5]. So, these types of hierarchy could reduce nuisances in the neighbourhood.

Cultural heritage sites cannot be overlooked in the inclusion of sustainable development policies. The decline of cultural identity causes the social aspect to lose dynamism against the economics and breaks the balance in the sustainable development basic triangle model, thus the environment and society should not be subjected to the economy.

The problem is to find new ways to slow down and stop the decay of the quality of life of society; however, this action requires time. Sustainable development should not be managed in terms of what it implies, but in terms of its effective implementation. So adequate city zoning conserves land for appropriate uses.

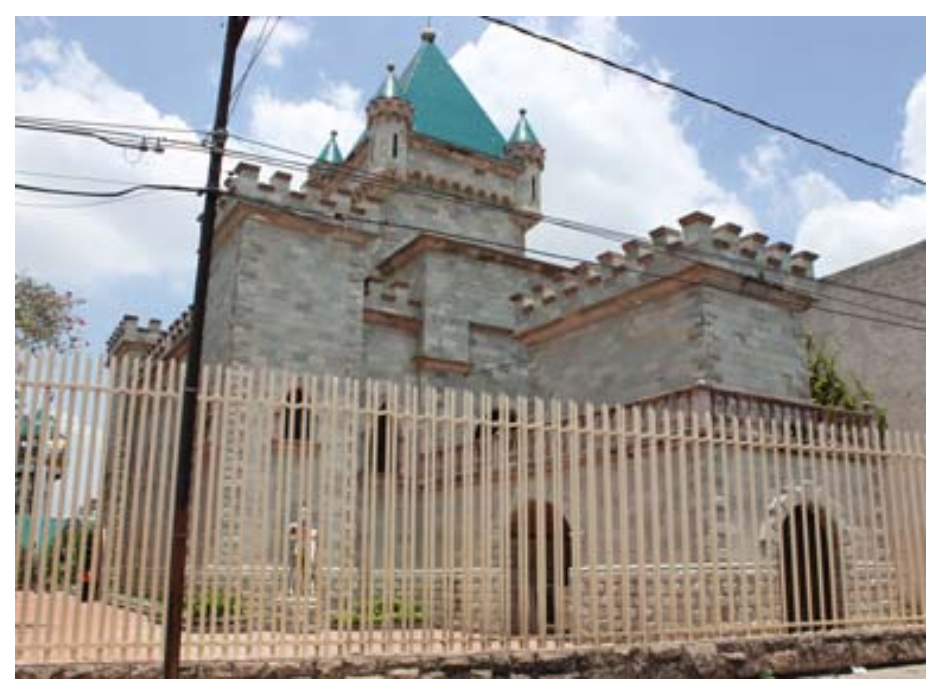

Figure 9: The theme park offers recreational opportunities for the workers of the company. (Photo: Rodríguez Torres, 2017.) 
Urban heritage needs a city planning strategy to protect valuable landmarks, without denying the historical time that is often changing and entering into a dialectic process that overcomes this encounter between inherent antagonisms of urban evolution, surpassing the limited role of the historical-cultural activities, such as the J. Gpe. Posada Museum. This perspective offers a possibility of preservation of monuments and cultural identity considering that the extinction of historical centres cannot be part of the evolution of cities.

It's useful to read the history in building (architecture itself contains history) that tells us what's happening in the city at certain moment of time - including social problems - in order to propose innovative, relevant and applicable urban designs with alternatives for the revaluation of urban heritage.

Perhaps it is time to consider most of the city as an urban heritage and not only the old significant areas. Even though the theme park of the JM Romo factory it's a new complex, according to the social acceptance demonstrated in the surveys applied in the writing of this paper, it could be considered as part of the local and regional identity.

In Aguascalientes there are buildings that should be considered as good architecture. Also, there are engineering works such as bridges, infrastructure and industrial buildings that can contribute to the current cultural integration. Maybe we need new ways to analyse the city because multiple aspects are part of the whole system. The streets, buildings, landmarks even the infrastructure, are part of a social heritage and it's up to the governments and citizens to take care of them. From this particular standpoint it would be more affordable to have sustainable environments.

\section{ACKNOWLEDGEMENTS}

I thank the following friends and students for their help: Luis Ocampo Sáenz, Mayté Esparza Díaz, Jéssica Alejandra Rodríguez Torres and Eduardo Alberto Rodríguez Valdez. Appreciation is extended to the researcher: Marco Alejandro Sifuentes Solís.

\section{REFERENCES}

[1] Groat, L. \& Wang, D., Architectural Research Methods, Wiley \& Sons, Inc.: United States of America and Canada, p. 88, 2002.

[2] Venturi, R. \& Brown, D.S. \& Izenour, S., Learning from Las Vegas, MIT Press: Cambridge, p. 34, 1977.

[3] Ruano, M., Ecourbanism. Sustainable human settlements: 60 case studies, Gustavo Gili: Barcelona, p. 20, 1999.

[4] Wilkinson, P., Restoration, the story continues..., BBC/English Heritage: United Kingdom, p. 14, 2004.

[5] Battle, G. \& McCarthy, C., Sustainable Ecosystems and the built environment, WileyAcademy: Italy, p. 91, 2001. 